\title{
VOCAL TRACT DYNAMICS IN AN ADULT STUTTERER
}

\author{
LESLEY WOLK, B.A. (SP \& H THERAPY) (WITWATERSRAND), \\ Department of Speech Pathology and Audiology, University of the Witwatersrand, \\ Johannesburg.
}

\begin{abstract}
SUMMARY
The present study was motivated by the clinical observation of "laryngeal spasms" during dysfluency in an adult female stutterer. The flexible fiberoptic nasolaryngoscope was employed in an attempt to assess this phenomenon objectively. Findings from fiberscopic and spectrographic investigations provided evidence for a disturbance in laryngeal behaviour, and in turn served to determine the nature of the treatment programme. Asymmetry of the vocal folds and partial abductory laryngeal behaviour, reflecting a conflict between adductory and abductory forces, characterized the dysfluency in this patient. A subjective evaluation after treatment revealed a reduction in both severity and frequency of stuttering behaviour. Furthermore, fiberscopic examination carried out after treatment revcaled an absence of the laryngeal disturbances noted previously. Results are considered in terms of vocal tract dynamics in stuttering and its clinical applicability.
\end{abstract}

\section{OPSOMMING}

Die kliniese waarneming van "laringeale spasmas" gedurende onvlotheid in 'n volwassc vroulike hakkelaar het die navorser beweeg tot verdere ondersoek van hierdie verskynsel. 'n Buigbare fiberskopiese nasolaringoskoop is gebruik in 'n poging om die verskynsel objektief te evalueer. Bevindings van fiberskopiese en spektografiese ondersoeke het bewys gelewer van 'n versteuring in laringeale gedrag, en het terselfdertyd ook die aard van die terapieprogram bepaal. Asimmetrie en gedeeltelike abduksie van die stemlippe wat 'n konflik tussen adduktor en abduktor kragte reflekteer, was 'n kenmerk van die pasiënt se onvlotheid. 'n Subjektiewe evaluasie na behandeling het 'n vermindering in beide die graad en frekwensie van hakkelgedrag getoon. ' $n$ Fiberskopiese ondersoek, wat na die behandeling uitgevoer is, het verder 'n afwesigheid van laringeale versteuring getoon. Resultate is geïnterpreteer teen die agtergrond van vokale kanaal dinamiek in hakkel en die kliniese toepassing daarvan.

Many years ago it was theorized that the larynx plays a significant role in stuttering (Kenyon ${ }^{9}$ ). Recently, investigations have provided some evidence for a relationship between phonatory behaviour and stuttering; the nature of which however, is still unclear (Adams and Hayden, ${ }^{1}$ Conture, McCall and Brewer, ${ }^{2}$ Freeman and Ushijima ${ }^{3}$, inter alia).

Modern technological advances have facilitated the use of several physiological measurement strategies in research with stutterers $\left(\right.$ Hutchinson $\left.^{8}\right)$. To date, none of these techniques has received more than isolated research interest. Furthermore, only little significant effort has been made to extend these experimental results to their practical clinical utility. This study was motivated by the clinical observation of "laryngeal spasms"! associated with dysfluency, during the course of therapy with an adult female stutterer. The flexible fiberoptic nasolaryngoscope (fiberscope) was thus employed to investigate the phonatory gestures in this patient. 
In this paper, the author's intention is:- (a) to discuss the fiberscopic examination in the ongoing assessment of this adult stutterer; (b) to briefly describe the treatment programme employed and (c) to discuss the overall findings in terms of vocal tract dynamics in stuttering and to consider some practical implications.

\section{BACKGROUND TO SUBJECT}

HISTORY OF SPEECH DISORDER: Mrs. A, aged 40 years, was first seen at the University Speech and Hearing Clinic, University of the Witwatersrand, Johannesburg, on the 21st March 1979.

Mrs. A reported that she had stuttered since childhood, which her mother associated with the bombing during the war. She was born in England and lived there for many years until recently when her husband was transferred to South Africa on a contract with a diamond mining company. About 18 months prior to the initial assessment, Mr. A suffered a traumatic head injury which resulted in bilateral deafness. Mrs. A stated that her stutter deteriorated noticeably since her husband's accident. At three stages of her life, Mrs. A received short periods of speech therapy, although on all these occasions she felt that she had not benefited.

MEDICAL HISTORY: She suffered from common childhood illnesses and underwent surgery for an eye defect. No other significant illnesses were reported.

PSYCHOLOGICAL AND FAMILY HISTORY: Mrs. A reported that she experiences much social discomfort since the onset of her husband's hearing impairment and the deterioration of her speech. She is said to share a warm relationship with her husband and three daughters. Two of her children are reported to stutter mildly.

\section{ASSESSMENT OF COMMUNICATION BEHAVIOUR}

The following areas were assessed by the author before the onset of treatment. Results are summarized in Table $I$.

\section{DESCRIPTION OF STUTTERING BEHAVIOUR}

Mrs. A was classified as an advanced stutterer. Her speech was characterized by frequent prolongations on fricatives, and several hard contacts on plosives, nasals and affricates in all positions. Hard contacts seemed to occur most frequently on voiceless plosives $/ \mathrm{p}, \mathrm{t}, \mathrm{k} /$ appearing as tense, forceful attacks combined with a severe tremor. The tension loci were in the lips, tongue, cheeks and laryngeal areas. This nonfluent speech pattern appeared to be habituated and consistent - some adaptation was noted.

There was evidence of severe facial tension, characterized by eye closure, eye rolling, frowning, jaw jerks, tremor of lips and flaring of nostrils. Upward movement of the head was noted to occur, as well as 
TABLE I: Summary of findings from an assessment of communication behaviour

\begin{tabular}{|ll|}
\hline Hearing & - within normal limits \\
\hline Oral Peripheral Examination & $\begin{array}{l}\text { - structural competence } \\
- \text { functional adequacy for speech }\end{array}$ \\
\hline Language & $\begin{array}{l}\text { - normal receptive and expressive } \\
\text { language skills }\end{array}$ \\
\hline Voice & - soft, high-pitched voice \\
\hline Articulation & - normal \\
\hline Rhythm, Stress, Phrasing & - interrupted \\
\hline Laterality & - established right (R) dominance \\
\hline Motor Co-ordination & \begin{tabular}{l} 
adequate \\
\hline Clinical observations
\end{tabular} \\
& $\begin{array}{l}\text { - reserved personality } \\
\text { tion } \\
\text { - insightful awareness and attentative- } \\
\text { ness }\end{array}$ \\
\hline
\end{tabular}

some movement of the extremities. There was associated disturbance of the respiratory mechanism such as pauses, gasping and frequent inhalations. She was often seen to cease a speech attempt and try again, and to employ starters with a sudden increase in tension and force. After a severe block, there was evidence of humiliation and intense anxiety. Eye contact was extremely poor. Choral speaking, singing, whispering and diminished auditory sensitivity were found to induce fluent speech. She was able to isolate several word and situation fears; the telephone being the most anxiety-provoking situation for her.

\section{DIAGNOSTIC INVESTIGATIONS OF LARYNGEAL BE- HAVIOUR}

FIBERSCOPIC ASSESSMENT

The fiberscope was employed to observe laryngeal beháviour directly during connected speech for the purpose of providing objective data that would assist in evaluating the role of the larynx in the dysfluency of this adult stutterer.

PROCEDURE

The patient's nasal passages and posterior aspects of the pharyngeal wall were topically anaesthetized to prepare for the insertion of the fiberscope. It was connected by a C-mount adapter to a camera. A 
diagnostic fiberoptic light source provided necessary illumination. The fiberscope was inserted into one nostril until the tip of the scope reached a level slightly rostral to the superior margin of the epiglottis. A tape recorder, Uher 4200 Report Stereo I.C. with an M816 directional microphone, was prepared to run concurrently with this examination so as to record all utterances. A transcription of the tape recordings was carried out as each utterance was correlated with its corresponding slide. There was a total of 38 slides. Broad-band spectrographic analyses with amplitude displays were carried out on each of these utterances in order to segment the duration of exposure, thus confirming whether the photograph was taken at the moment of the stuttered block. It was always entirely clear, both from broad-band spectrograms and the amplitude displays when the shutter had opened and closed. For the purpose of this paper, only a few of these utterances were selected in order to highlight the major findings.

\section{RESULTS}

Figures $1(a)$ and $(b)$ show that the vocal cords are normal at rest and during deep inhalation respectively. Figure 2(a) shows a stuttering block on $/ \mathbf{k} /$ in the word "cancellations". From observation during fiberscopic examination, it appeared that there was asymmetry of the vocal folds relative to each other. Posteriorly at the vocal processes, the left (L) cord is more adducted than the right (R) cord. There is also clear asymmetry of the arytenoid cartilages. It can be seen that there is a conflict between adductory and abductory forces, which may be referred to as "partial abductory" laryngeal behaviour. The same asymmetry appears as the standard picture of a characteristic block on other plosive sounds (voiced and voiceless) in initial and medial positions. The broad-band spectrogram in Figure $2(b)$ confirms the fact that this photograph was taken at the moment of the stuttered block. The first noise burst, marked $\mathrm{S}(\mathrm{O})$ on the spectrogram, refers to when the shutter opened and the second noise burst, marked $S(C)$, refers to when the shutter closed.

In Figure 3(a) similar partial abductory laryngeal behaviour can be seen during a sound prolongation on $/ \mathrm{s} /$ in the word "sweater". The broad-band spectrogram in Figure $3(b)$ provides confirmation as in Figure $2(b)$ above. During observation of the vocal cords, there was evidence of epiglottic movement and shuddering of the entire larynx during dysfluency. This figure clearly illustrates the standard picture of asymmetry where the (R) fold appears more prominently than the (L) one. The distances between the vocal cords were measured. Results revealed that the distance posteriorly was 5 units of measurement, medially 3 units and anteriorly 4 units*. The anterior measurement was taken at the point where the folds seem to shade off, i.e.

*It is not claimed that these are absolute glottal widths, as the degree of magnification has not been computed, but the proportions are correct. 


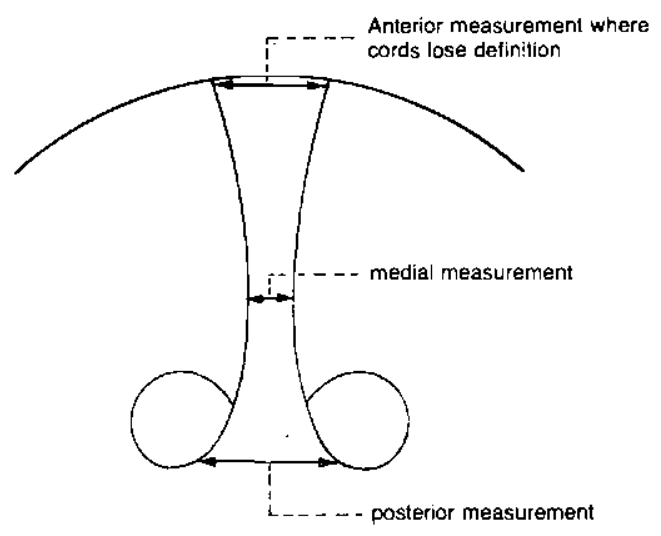

Notice that there is medial adduction which is abnormal. Thus the narrowest portion of the glottis is medial, while the posterior and anterior portions are both wider, reflecting a disturbance in normal largyngeal behaviour. The striking feature was this recurring picture of arching, which will be referred to as the "arched effect".

In summary, a review of the tape recordings and corresponding slides, together with measurements of the glottis calculated for each utterance, revealed the following:

1. The vocal folds were normal at rest and during deep inhalation. They were parallel and symmetrical during all fluent utterances and during singing.

2. There was a general picture of shuddering of the larynx during dysfluency.

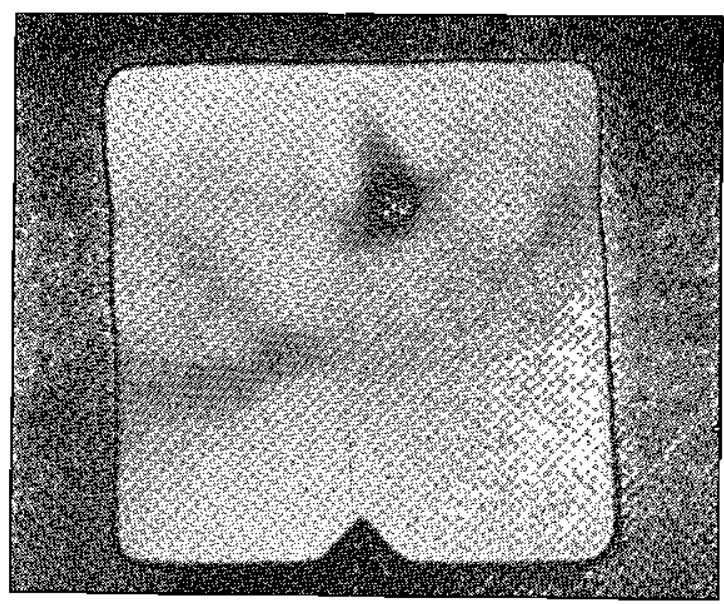

A

Figure 1(a) Subject Mrs. A's laryngeal behaviour during quiet breathing, showing that the vocal cords are normal at rest.

The South African Journal of Communication Disorders, Vol. 28, 1981 
3. There was evidence of asymmetry of the arytenoids and vocal cords during all dysfluent utterances, where the $(R)$ fold appeared more prominently than the $(\mathrm{L})$ one.

4. Partial abductory laryngeal behaviour referred to as the "arched effect", characterized all dysfluency, stuttering blocks and prolongation in all positions. The identical picture was observed with voiced and voiceless fricatives, affricates and plosives.

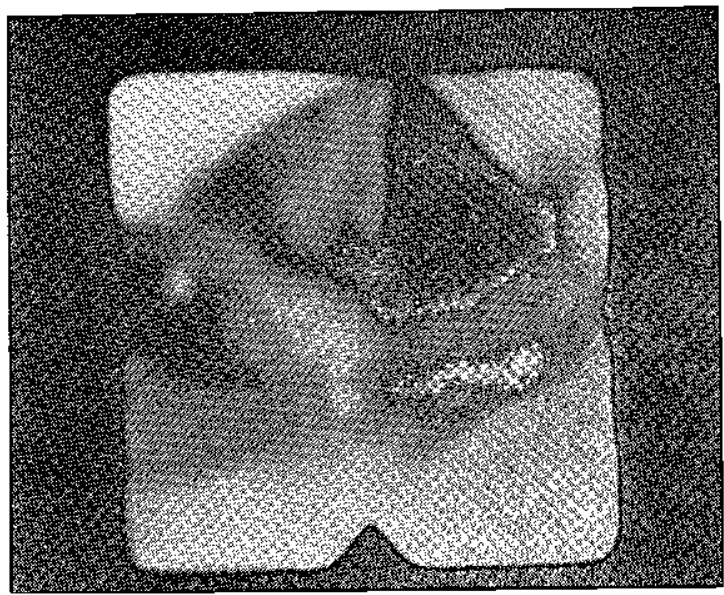

B

Figure 1(b) Subject Mrs. A's laryngeal Behaviour during deep inhalation, showing that the vocal cords are normal during deep breathing.

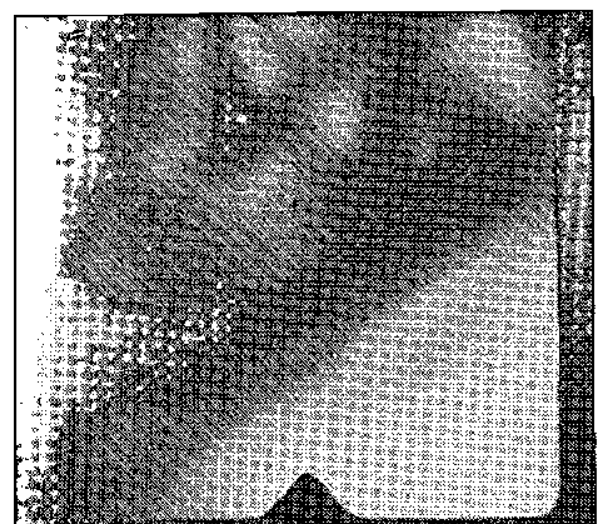

A

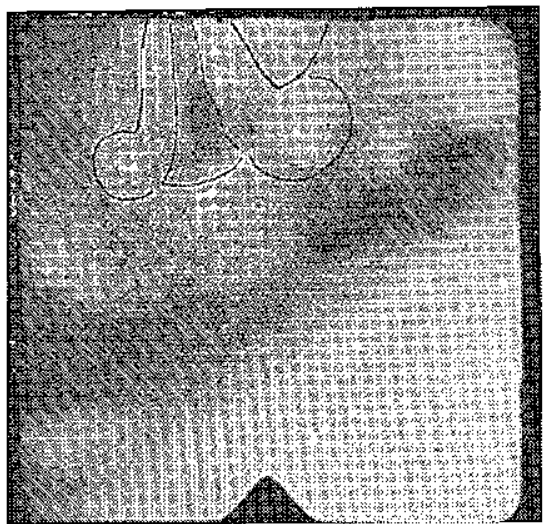

B

Figure 2(a) Laryngeal behaviour during a stuttering block on $/ \mathrm{k} /$ in "cancellations". The line-tracing which overlays B, outlines the laryngeal structures shown during this production.

Die Suid-Afrikaanse Tydskrif vir Kommunikasieafwykings, Vol. 28, 1981 


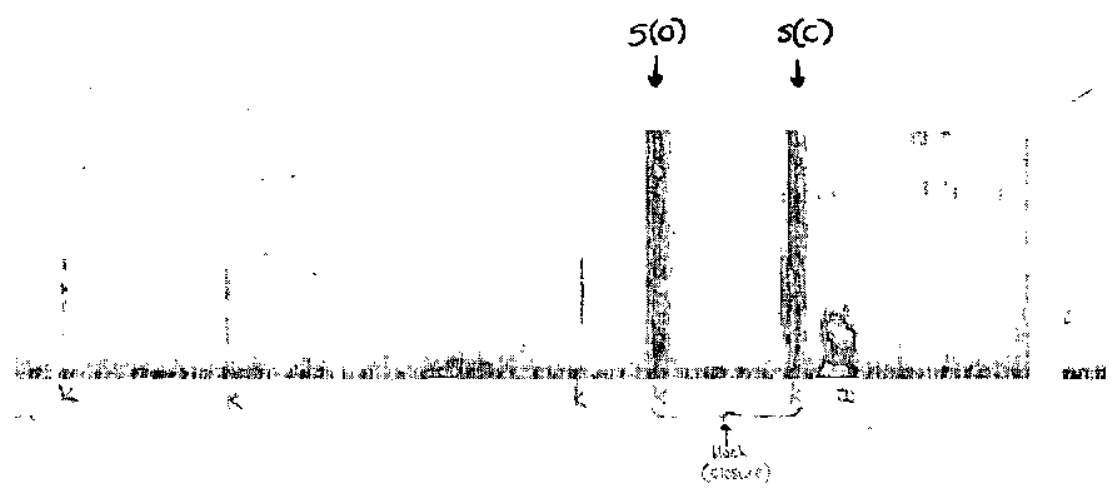

Figure 2(b) Broad-band spectrogram showing a block on dysfluent production of $/ \mathrm{k} /$ in "cancellations" before treatment.

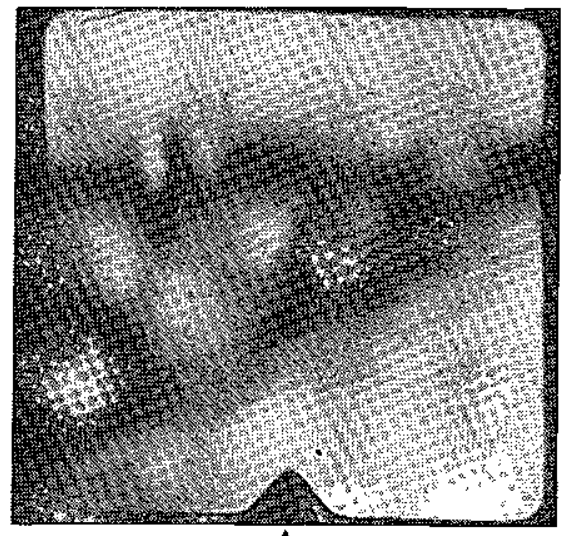

A

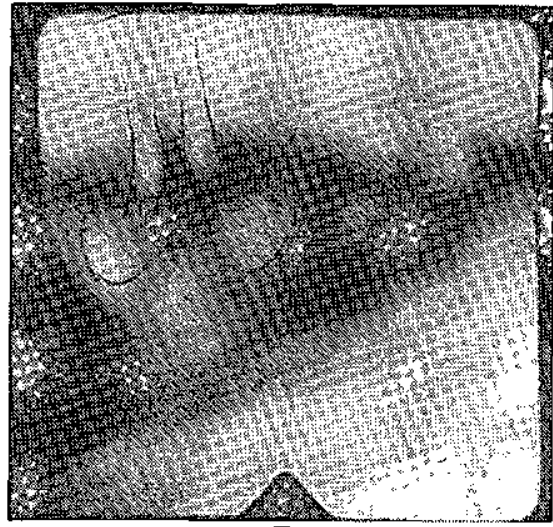

B

Figure 3(a) Laryngeal behaviour during prolongation on $/ \mathrm{s} /$ in "sweater". The line-tracing which overlays B outlines the laryngeal structures shown during this production.

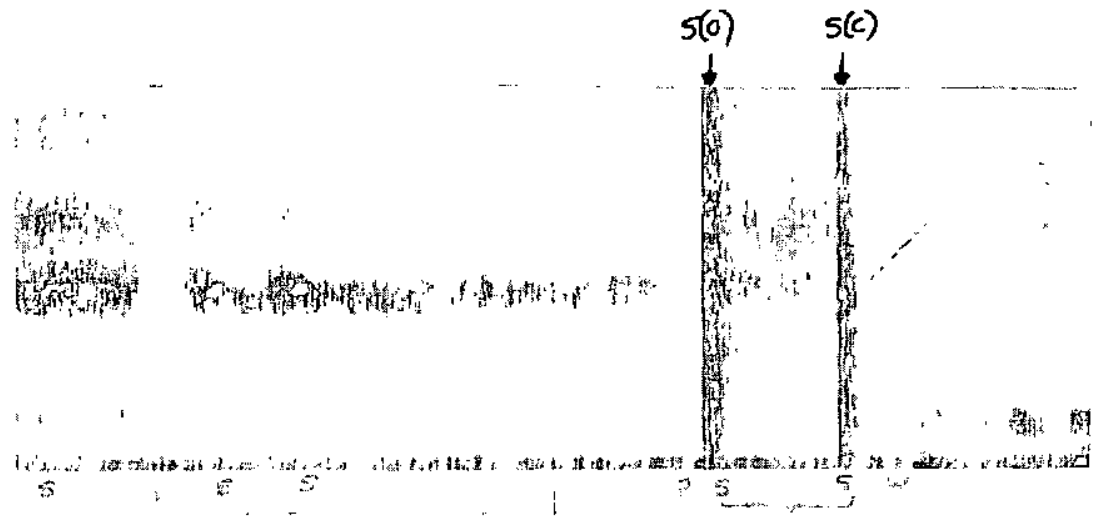

Figure $3(b)$ Broad-band spectrogram showing a prolongation on dysfluent production of /s/ in "sweater" before treatment.

The South African Journal of Communication Disorders, Vol. 28, 1981 
DISCUSSION

Abductory laryngeal behaviour during stuttering is reported in several recent studies (Conture et $\mathrm{al}^{2}$ ). However, the specific picture of asymmetry ("arched effect") reflecting a conflict between adductory and abductory forces, characteristic of the dysfluency in this subject, has not been reported in the literature. In contrast to the present data, Conture et $\mathrm{al}^{2}$ found differences in laryngeal behaviour among the various types of stutterings. They found a separation of the posterior aspects of the vocal folds during part-word repetitions, but normal laryngeal behaviour in sound prolongations.

Literature on normal vocal cord function in man shows that:adduction of the vocal cords for phonation is due to the contraction of the vocalis (VOC), lateral cricoarytenoid (LCA) and interarytenoid (INT) muscles; whilst abduction is due to the contraction of the posterior cricoarytenoid (PCA) muscle (Hiroto, Hirano, Toyozumi and Shin $^{7}$ ). The VOC muscle and to a lesser degree the LCA muscle regulate the style of phonation. They are active in the medial compression of the vocal cords to produce inner tension of the cords. Three "styles of phonation" are generally considered: hypertense, hypotense and optimum styles (Freeman et $\mathrm{al}^{3}$ ). With regard to complexity of laryngeal movements preparatory to vocalization, three types of vocal attack are commonly described (a) soft attack (simultaneous) where PCA activity is suppressed throughout the pre-phonatory period; LCA and VOC activity increase gradually until it reaches a constant level shortly before or after the vocal onset, (b) hard attack (glottal) where PCA activity decreases well before the onset of voicing, shows a transient increase in activity just before the onset of voicing and is then suppressed for the period of voicing; there is a high level of LCA and VOC activity, presenting forceful action potentials before phonation, and (c) breathy attack (aspirate) where PCA remains active throughout the pre-phonatory period up to the point immediately before the onset of voicing. LCA and VOC activity is often decreased temporarily before phonation. Therefore, the type of vocal attack depends on vocal cord placement at the initiation of voicing, which is determined by the precise co-ordination between sub-glottic pressure, glottal resistance and supraglottic pressure. (Gay, Strome, Hirose and Sawashima ${ }^{5}$ ).

It thus seems reasonable to postulate that in this adult stutterer, there may be higher levels of VOC and/or LCA muscle activity (adductors) and inappropriate functioning of the PCA muscle (abductor), resulting in a disturbance of the interplay between agonist and antagonist intrinsic laryngeal muscles during stuttering. The fact that the cords are abducted posteriorly would indicate that there is adequate functioning of the interarytenoid muscles. The VOC and LCA muscles are thus considered responsible for the relative hypertonicity of the adductors. These findings are in accordance with current research (Conture et al, ${ }^{2}$ Freeman and Ushijima ${ }^{3}$ ). It appears that the difficulty may lie in the 
pre-phonatory and/or re-phonatory phase, whereby voicing is initiatied with hard vocal attacks resulting in a hypertense style of phonation. There is evidence in the literature to support the belief that some stutterers fail to produce adequate voluntary pre-setting of the phonatory musculature, and that there is a lack of co-ordination between respiration, articulation and phonation in stuttering (Gautheron, Liorzou, Even and Vallancien, ${ }^{4}$ Perkins, Rudas, Johnson and Bell $\left.^{11}\right)$. Wyke ${ }^{17}$ and others would explain findings such as these in terms of the reflex arc, whereby higher centres control laryngeal reflex activity. According to this model, psychological stresses affect the supramedullary centres which fail to inhibit PCA muscle activity, producing abductive responses to the larynx during stuttering.

\section{TREATMENT:}

A treatment programme incorporating the psychological aspects as well as modification of the faulty laryngeal adjustments developed from the diagnostic findings discussed above. Only a brief discussion of this programme will be included in this paper.

Set within a Van $\operatorname{Riper}^{15}$ framework, various techniques were employed within the modification phase of therapy. These included Van Riper's ${ }^{15}$ shaping processes, "prolonged speech" $\left(\right.$ Perkins $^{10}$ ), "passive-airflow technique" (Schwartz ${ }^{13}$ ), "precision fluency shaping" as discussed by Webster ${ }^{16}$ and "modification of vocal attack" developed by the author.

\section{MODIFICATION OF VOCAL ATTACK}

Considering hard attack to be the error pattern with high levels of VOC and LCA muscle activity and significantly earlier voice onset time, one may view soft attack as the target behaviour representing optimal muscular activity. In view of the fact that breathy attack reduces VOC and LCA muscle activity temporarily before phonation, thus facilitating gradual voice onset, it was employed as a therapeutic strategy (Gautheron et $\mathrm{al}^{4}$ ). Furthermore, there is continuous PCA muscle activity during the pre-phonatory period in breathy attack, thus preventing jerky "on-off" vocal adjustments. Breathy phonation was combined with a low pitch in order to further reduce electrical activity during phonation (Gay et $\mathrm{al}^{5}$ ). A marked reduction in dysfluency was noted to occur when this method was employed in a variety of speech tasks.

A further technique, biofeedback, was applied. The underlying principle of biofeedback training is that a subject can léarn to exert some control over a physiological process if he receives immediate, accurate (auditory or visual) information about the process (Hanna, Wilfling and $\mathrm{McNeill}^{6}$ ). Briefly, EMG activity was recorded from the laryngeal and facial areas where there was excessive tension. A pair of surface electrodes were placed on the skin over the levator labii superioris. The action potentials from this muscle were amplified and 
integrated into a voltage-to-frequency converter. As the electrical activity of the muscles increased, so did the frequency of the EMG analog tone. Mrs. A was provided with a baseline or reference frequency. She was then presented with a tone whose frequency was analogous to the voltages recorded from the electrodes and her task was to concentrate on lowering this tone, hence lowering the muscular hypertonicity. A second electrode pair was placed over the orbicularis oris and a third electrode pair over the cricothyroid region below the thyroid notch. Each time the same procedure was carried out. An informal assessment during the sessions and a subsequent replay of the tape recordings demonstrated that there was a significant reduction in laryngeal EMG activity with a concomitant increase in fluency. No conclusions can be drawn from this preliminary investigation. However, it is conceivable that after sufficient training, a stutterer could learn to attend to somesthetic cues of laryngeal tension in the absence of biofeedback equipment. It is of interest to note that in the study of Gautheron et $\mathrm{al}^{4}$, their stutterers were encouraged to start phonating breathily while attempting to obtain auto-correction with the aid of visual feedback.

In summary, gaining conscious control of speech production by reconstructing articulatory details, enhancing proprioceptive awareness, encouraging smooth transition of laryngeal adjustments and altering the tension of the vocal cord musculature, seems to be the features common to the modification techniques employed in this treatment programme.

\section{RESULTS OF TREATMENT}

A subjective evaluation after treatment revealed a significant reduction in both severity and frequency of stuttering behaviour. There appeared to be very little facial, neck and laryngeal tension or associated movements. Furthermore, there was evidence of improved self-concept and personal adjustment. Towards the end of treatment, a further fiberscopic examination was carried out in order to compare Mrs. A's laryngeal behaviour before and after treatment. The entire procedure followed that described above. There was a total of 141 utterances (from spontaneous speech) with corresponding slides.

Figure 4(a)- $A$ shows a stuttering block on $/ \mathrm{k} /$ in "cancellations" before treatment, reflecting the asymmetrical "arched effect" with partial abductory laryngeal behaviour. Figure $4(a)-B$ shows a stuttering block on $/ \mathrm{k} /$ in "keen" after treatment. Here it can be seen that the glottis is wide open for the voiceless plosive $/ \mathrm{k} /$ and there is an absence of the asymmetrical "arched effect" seen in (A). Similarly in Figure 5(a)-B it can be seen that there is an absence of the arching in the sound prolongation /s/ in "this sea" after treatment. The apparent asymmetry is not due to the original "arched effect", but is due to the asymmetry of the false cords. 


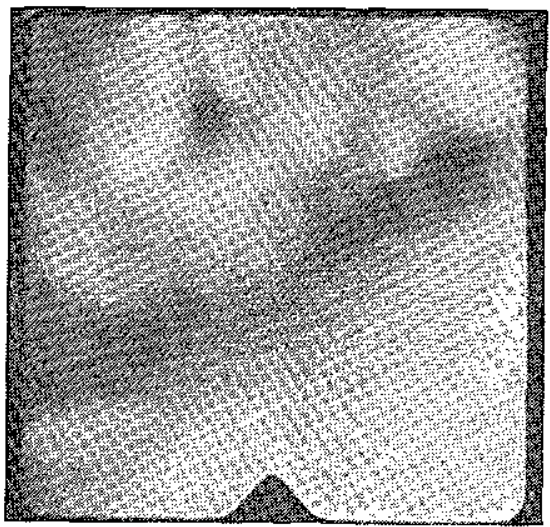

A

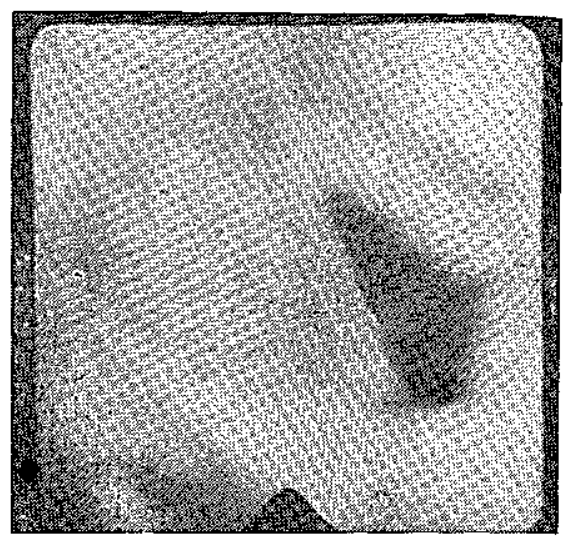

B

Figure 4(a) Laryngeal behaviour on (A), a stuttering block on $/ \mathrm{k} /$ in "cancellations" before treatment, and (B), a stuttering block on $/ k /$ in "keen" after treatment.

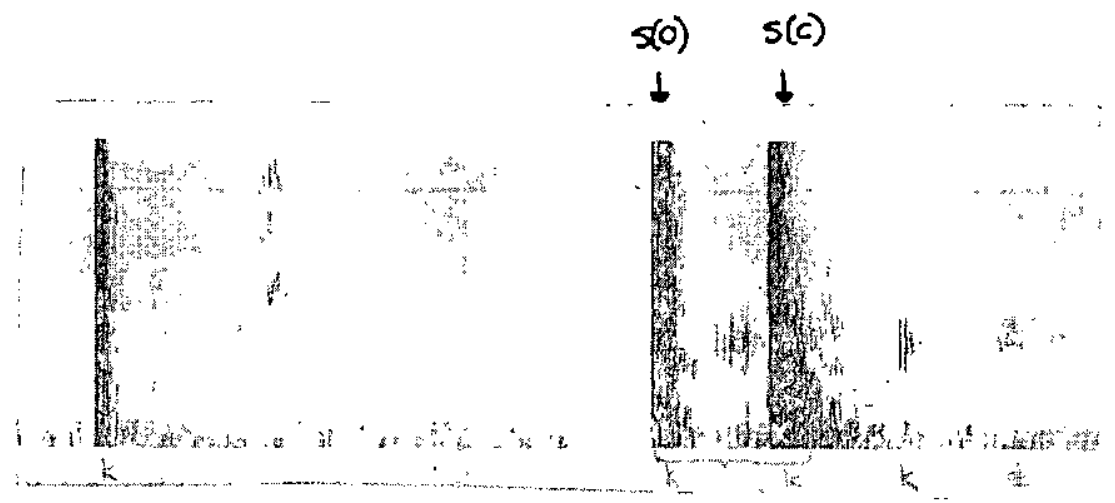

Figure 4 (b) Broad-band spectrogram showing a block on dysfluent production of $/ \mathrm{k} /$ in "keen" after treatment.

In each case, broad-band spectrograms confirmed that the photographs were taken at the instance of the stuttered block (see Figures $2(b)$, $3(b), 4(b)$ and $5(b))$. The fibrescopic representations described here were chosen at random for the purpose of this discussion. However, these representations are characteristic of the standard dysfluencies (stuttering blocks and prolongations) throughout all utterances analysed after treatment.

An obvious limitation should be considered in the interpretation of these results. Increased tension may have been created by the initial 

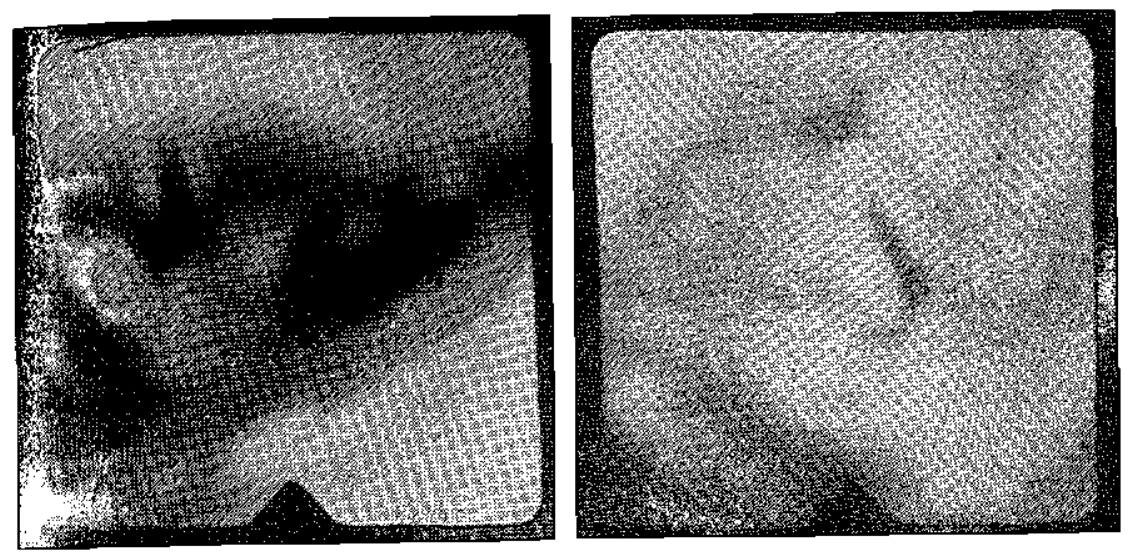

Figure 5(a) Laryngeal behaviour on (A), a sound prolongation /s/ in "sweater" before treatment, and (B), a sound prolongation /s/ in "this sea" after treatment.

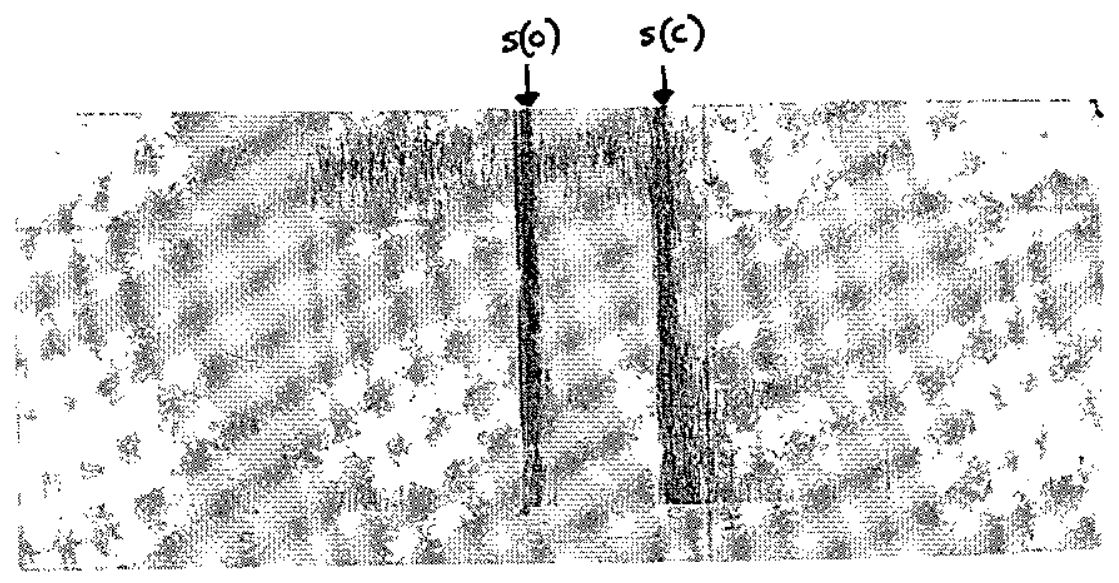

Figure 5(b) Broad-band spectrogram showing prolongation on dysfluent production of $/ \mathrm{s} /$ in "this sea" after treatment.

Note: The peak value of PCA laryngeal muscular activity is the same for $/ \mathrm{s} /$ sounds in different positions, initially and medially (Hirose and Ushijima, 1974).

Die Suid-Afrikaanse Tydskrif vir Kommunikasieafwykings, Vol. 28, 1981 
fiberscopic procedure resulting in increased stuttering, and conversely the familiarity of the procedure after treatment may have reduced stuttering. However, qualitative assessments of the tape recordings during both procedures were found to be representative when compared with tape recordings of her speech outside of the fiberscopic investigations.

\section{CONCLUSIONS AND IMPLICATIONS}

The present findings support the contention that laryngeal disturbances are associated with many moments of stuttering (Conture et $\mathrm{al}^{2}$ ). While this may explain the proximal cause of stuttering, we are still faced with the question of "primary causation".

In a recent study, Schmitt and Cooper ${ }^{12}$ found no laryngeal abnormalities in a group of young stutterers. This leads one to question whether the differences observed in the phonatory behaviour of adult stutterers might be more a reflection of habituated compensatory phonatory adjustments in response to dysfluencies than they are indicators of an etiological key to stuttering. While reference has been made to some underlying neurologic fault in some stutterers, (for example, faulty laryngeal innervation, flaws in temporal lobe sequencing, a deficit in auditory feedback systems or aberrant inter-hemispheric relationships (Wyke, ${ }^{17}$ Travis $^{14}$ ), there is also convincing information that psychological factors must be considered. Thus a multidimensional etiology of the manifestations of stuttering behaviour as suggested by Van Riper ${ }^{15}$ still seems plausible.

The unresolved etiology of stuttering should not, however, restrict the continued search for treatment methods. The benefits of intensive stuttering therapy in this case are clearly indicated. These findings pertain to a single case of stuttering. They are thus tentative and should be regarded as an indication for further research. Future investigations in biofeedback as a treatment for stuttering is strongly indicated. Thus, an attempt to integrate research on laryngeal dysfunction in stuttering with learning-theory and servo-theory might well be of clinical value.

\section{ACKNOWLEDGEMENTS}

The author wishes to thank Mrs. M. Wahlhaus, Senior Lecturer of the Department of Speech Pathology and Audiology, and Ms. C. Penn, Lecturer of the Department of Speech Pathology and Audiology, of the University of the Witwatersrand, Johannesburg, for their guidance and support; Dr. A. Traill, Senior Lecturer of the Department of Phonetics and General Linguistics for his valuable assistance in the spectrographic and fiberscopic testing of this patient; Dr. E. Gordon and Dr. A. Gordon for their assistance with the biofeedback procedure. The author also acknowledges the Human Sciences Research Council for its financial assistance. 


\section{REFERENCES}

1. Adams, M. R. and Hayden, P. (1976): The ability of stutterers and non-stutterers to initiate and terminate phonation during production of an isolated vowel. J. Speech, Hear. Res. 19, 290-296.

2. Conture, E. G., McCall, G. N. and Brewer, D. W. (1977): Laryngeal behaviour during stuttering. J. Speech. Hear. Res. 20, 661-668.

3. Freeman, F. J. and Ushijima, T. (1978): Laryngeal muscle activity during stuttering. J. Speech. Hear. Res. 21(3), 538-562.

4. Gautheron, B., Liorzou, A., Even, C. and Vallacien, B. (1973): The role of the larynx in stuttering. In: Neurolinguistic Approaches to Stuttering: Proceedings of the International Symposium on Stuttering. Le Brun, Y. and Hoops, R. (Eds) Mouton, The Hague.

5. Gay, T., Strome, H., Hirose, H. and Sawashima, M. (1972): Electromyography of the intrinsic laryngeal muscles during phonation. Ann. Otol. Rhinol. Laryngol. 81, 401-408.

6. Hanna, R., Wilfling, F, and McNeill, B. (1975): A biofeedback treatment for stuttering. J. Speech. Hear. Dis. 40, 270-273.

7. Hiroto, I., Hirano, M., Toyozumi, Y. and Shin, T. (1967): Electromyographic investigation of the instrinsic laryngeal muscles related to speech sounds. Ann. Otol. Rhinol. Laryngol. 76, 861-872.

8. Hutchinson, J. M. (1974): Aerodyamic Patterns of stuttered speech. In: Vocal Tract Dynamics and Dysfluency. Webster, L. M. and Furst, L. (Eds). Speech and Hearing Institute, N.Y., $71-88$.

9. Kenyon, E. L. (1943): The etiology of stammering: the psychophysiologic facts which concern the production of speech sounds and stammering. J. Speech. Dis. 8, 337-348.

10. Perkins, W. H. (1979): From psychoanalysis to disco-ordination. In: Controversies about Stuttering Therapy. Gregory, H. H. (Ed). University Park Press, Baltimore.

11. Perkins, W. H., Rudas, J., Johnson, L. and Bell, J. (1976): Stuttering: Disco-ordination of phonation with articulation and respiration. J. Speech. Hear. Res. 19, 509-521.

12. Schmitt, L. S. and Cooper, E. B. (1978): Fundamental frequencies in oral reading behaviour of stuttering and non-stuttering male children. J. of Comm. Dis. 11, 17-23.

13. Schwartz, M. F. (1976): Stuttering Solved. (Part II) The Treatment. Lippincott. J. B. Co., Redwood, Burn. Ltd. Trowbridge and Escher.

14. Travis, L. E. (1978): The cerebral dominance theory of stuttering 1931-1978. J. Speech. Hear. Dis. 43, 278-281.

15. Van Riper, C. (1973): The treatment of stuttering. Prentice-Hall Inc., Englewood Cliffs, N.J. 
16. Webster, R. L. (1977): A few observations on the manipulation of speech response characteristics in stutterers. In The problems of Stuttering - Theory and Therapy. Reiber, R. W. (Ed). Elsevier North-Holland, Inc. N.Y., 73-76.

17. Wyke, B. (1974): Phonatory reflex mechanisms and stammering. Folio Phoniat. 26, 321-338.

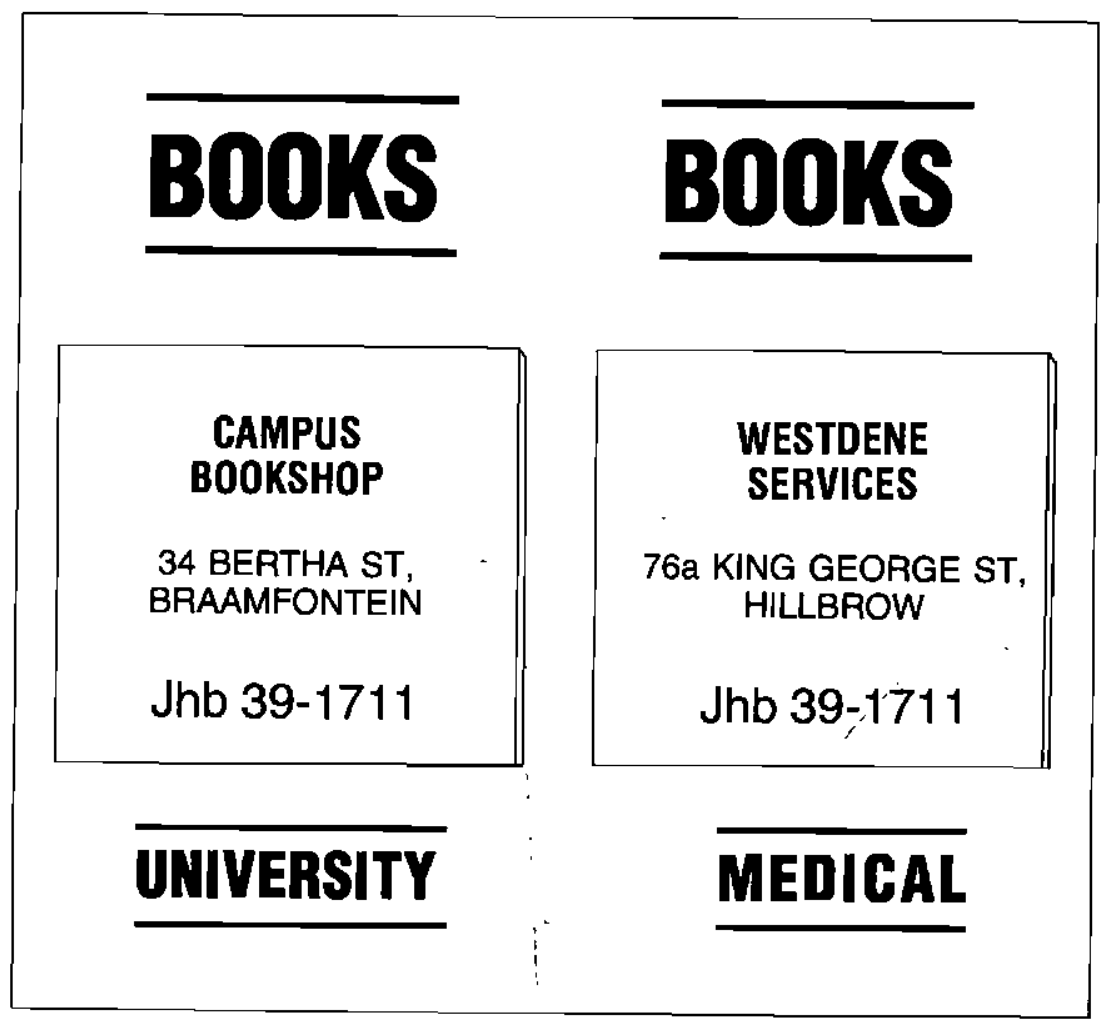

